\title{
Infrequent tooth brushing and teeth lost may increase the risk of oral and pharyngeal cancers: A nationwide population-based cohort study in Korea.
}

Ho Geol Woo

Ewha Women's University College of Medicine

Kijeong Lee

Eunpyeong St. Mary's Hospital, Catholic University of Korea

Ji Sung Lee

Asan Medical Center

Jinkwon Kim

Gangnam Severance Hospital

Younkyung Chang

Ewha Women's University College of Medicine

Jin-Woo Kim

Ewha Women's University College of Medicine

Tae Jin Song ( $\sim$ knstar@ewha.ac.kr)

Ewha Women's University College of Medicine https://orcid.org/0000-0002-9937-762X

Research article

Keywords: Oral hygiene, Oral cancer, Tooth brushing, General population, Longitudinal study

Posted Date: June 2nd, 2020

DOI: https://doi.org/10.21203/rs.3.rs-18434/v2

License: (c) (7) This work is licensed under a Creative Commons Attribution 4.0 International License. Read Full License 


\section{Abstract}

Background: Oral and pharyngeal cancers are emerging and troublesome diseases worldwide. Although poor oral hygiene behaviors and parameters affecting oral health have been considered as potential risk factors of oral and pharyngeal cancers including smoking and alcohol consumption for decades, study results have been inconsistent. Longitudinal studies regarding the association between poor oral hygiene behaviors and parameters of oral health and the occurrence of oral and pharyngeal cancers have been lacking. We aimed to investigate this relationship in a nationwide general population-based cohort.

Methods: We included data on demographics, past history, and laboratory findings for 150,774 subjects without teeth lost from the Korean National Health Insurance System-Health Screening Cohort. The presence of periodontal disease and parameters of oral health, including frequency of tooth brushings, dental visits for any reason, professional teeth scaling, and number of teeth lost, were investigated. Oral and pharyngeal cancers were defined by the International Statistical Classification of Diseases, $10^{\text {th }}$ Revision, codes of C00-C14.

Results: During a median 11.1 years of follow-up, 1,155 (0.77\%) oral and pharyngeal cancers occurred. Based on multivariable analysis, after adjusting for demographics, alcohol consumption, smoking status, regular exercise, body mass index, systolic blood pressure, blood and urinary laboratory findings, and parameters of oral health including frequent tooth brushing (three or more times per day) were related to a lower risk of oral and pharyngeal cancers (hazard ratio [HR]: $0.78,95 \%$ confidence interval [Cl]: 0.66-0.93, $p=0.005)$. An increased number of teeth lost $(\geq 15)$ was positively associated with occurrence of oral and pharyngeal cancers (HR: 1.71, 95\% Cl: 1.26-2.31, $\mathrm{p}=0.001$ in model 1; HR: 1.68, 95\% Cl: 1.24-2.28, $\mathrm{p}<0.001$ in model 2; HR: 1.66, 95\% Cl: 1.22-2.25, $\mathrm{p}=0.001$ in model 3 ; $\mathrm{p}$-value for trend test for $\mathrm{HR}<0.001$ ).

Conclusions: The occurrence of oral and pharyngeal cancers decreased with more frequent tooth brushing (three or more times per day) and increased with the number of teeth lost. With regards to the prevention of oral and pharyngeal cancers, improving oral hygiene may have a significant contribution.

\section{Background}

Oral and pharyngeal cancers, which are globally the sixth most common cancers, are emerging and troublesome diseases worldwide [1]. Although recent advances in medicine have improved survival rates, the prognosis of oral and pharyngeal cancers has remained poor and significantly unimproved over the last three decades [1, 2]. Therefore, identifying and controlling the risk factors or causative factors of oral and pharyngeal cancers are important. To date, although major risk factors such as human papillomavirus (HPV) infection, smoking, and alcohol consumption and protective factors such as consumption of coffee, vegetables, fruit, and dietary folate intake have been investigated [2,3], information regarding other risk factors or related factors remains unknown and requires additional research.

Periodontal disease, which includes gingivitis and periodontitis, is closely associated with oral hygiene [4]. Although poor oral hygiene and periodontal disease have been considered as potential risk factors for oral cancer for decades, study results have been inconsistent [5-7]. Some previous studies found that insufficient oral sanitation can induce chronic systemic inflammation, and this inflammatory process is a well-known mediator of oral cancer [8, 9]. Another study suggested that the chronic inflammatory reaction process, which includes a weakening of the host's immune system that induces cell proliferation and promotes prolonged cell survival, results in the development of malignancy [10].

In a previous cohort study, poor oral hygiene, as evidenced by number of teeth lost, frequency of dental check-ups, and frequency of tooth brushings, was identified as an emerging risk factor for oral cancer [11]. Moreover, a previous systemic review and meta-analysis of case-control studies showed that periodontal disease was related to a significant increase in the risk for oral cancer $[12,13]$. Other case-control studies reported that poor oral health, loss of multiple teeth, and infrequent tooth brushing are related to the risk of upper aerodigestive tract cancers, including in the lips, oral cavity, oropharynx, hypopharynx, larynx, and esophagus [14, 15]. However, studies investigating the relationship between parameters of oral health and periodontal disease and the occurrence of oral and pharyngeal cancers are sparse in the longitudinal setting.

The aim of the present study was to investigate the relationship between parameters of oral health and the risk of oral and pharyngeal cancers in a nationwide general population-based cohort.

\section{Methods}

\section{Database}

The National Health Insurance System (NHIS) includes databases of demographics, kinds of covered health insurance, socioeconomic status, treatment and diagnosis modalities, and medical care institutions, in addition to a nationwide-supported health examination. This system consists of health information from a random sampling of 50 million Koreans [16]. It is the single health insurance provider offered by the Korean government. A total of $97 \%$ and $3 \%$ of the healthcare services for the Korean population are provided by the NHIS and the Medical Aid program, respectively. Since 2002, members of the system have been advised to undergo biannual uniformed health examinations [17]. Subjects from the NHIS-Health Screening Cohort (NHIS-HEALS) were enrolled in the present study [18]. The NHIS oral health screening program is provided to subscribers $\geq 40$ years of age. The program consists of self-reported surveys including information regarding dental symptoms, oral hygiene behavior, and dental visits during the last year. In addition, dentists check the oral health status of the subjects, including the number of teeth lost. If oral health is poor, participants are advised on improvements to oral hygiene practice as necessary [19].

\section{Study population}

The present study is a retrospectively analysed longitudinal study in which 2003-2004 data from a cohort of adult subjects 40-79 years of age were evaluated. In order to rule out the possibility of hidden malignancy, the study was conducted with datasets from 2003 to 2004 , taking into account the 
washout period of one year from 2003. From 2 weeks to 12.9 years as range of follow up, we evaluated development of oral and pharyngeal cancers in the medical treatment database. Among 514,866 total participants, those who had missing data in oral health status $(n=343,037)$, health examination ( $n=8,094)$, or previous history of any malignancy $(n=12,961)$ were excluded. Finally, the complete case dataset of 150,774 subjects was investigated in the present study (Figure 1).

\section{Study variables and definitions}

\section{Exposure variables}

Oral hygiene behaviors (professional teeth scaling, dental visits for any reason, and the frequency of tooth brushings) were acquired from self-reported surveys of oral health examination [19]. Frequency of tooth brushings was categorized as three or more times per day, twice per day, and none or one time per day. Professional teeth scaling and dental visits for any reason were dichotomized (i.e., at least one time per year or never). If the subject received professional teeth scaling or had a dental visit once every two years, the subject was classified into the never group. The number of teeth lost was checked by dentists during the oral health examination [19]. The number of teeth lost was classified regardless of the cause $(\geq 15,8-14,1-7$, and 0$)$. The index date was indicated as the date of the examination for oral health status. If two or more examinations for oral health were performed between 2003 and 2004 , the most recent examination was used for the analysis.

\section{Outcome variables}

The main study outcome was the occurrence of oral and pharyngeal cancers, which was defined as the presence of at least one of the International Statistical Classification of Diseases, $10^{\text {th }}$ Revision (ICD-10) codes for oral and pharyngeal cancers, defined as C00-C14, in the medical treatment database. Based on previous studies, the ICD-10 codes for the specific cancers are defined as follows: C00-C06, oral cavity and oral cancer; C07-C08, salivary gland cancer; and C09-C14, tonsil and pharynx cancer [20,21]. Subjects with a diagnosis of oral and pharyngeal cancers before the index date were excluded. Diagnosis using ICD-10 codes has already been validated by comparison with the Korean National Cancer Incidence Database. The overall sensitivity of cancer diagnosis using the ICD-10 codes was $92.8 \%$ [22].

\section{Confounding variables}

The definition of comorbidity is described in the Supplementary file (Additional file 1). Based on previous studies, the presence of periodontal disease was defined as when one of the relevant ICD-10 codes (aggressive periodontitis [K05.2], chronic periodontitis [K05.3], periodontosis [K05.4], other periodontal disease [K05.5], and unspecified periodontal disease [K05.6]) was claimed two or more times by a dentist or when a subject was treated for periodontal disease (ICD-10 codes K05.2-5.6) by a dentist [19, 23, 24].

\section{Statistical analyses}

The Chi-square test and independent $t$-test were conducted to compare categorical and continuous variables, respectively. To compare demographic data of included subjects with those of excluded subjects, due to the possibility of false positives in large sample size data from the Chi-square test and independent $\mathrm{t}$-test, we investigated the standardized difference between the groups. If the standardized difference is greater than 0.1 with absolute value, it is concluded that there is a difference between included subjects and excluded subjects. Cumulative incidence curves analyses were conducted using Gray's Test to evaluate the relationship between periodontal disease and parameters of oral health and incidence of oral and pharyngeal cancers.

The Fine and Gray regression methods were used for competing risk data since death was a competing event for oral and pharyngeal cancers. Hazard ratios (HR) and $95 \%$ confidence intervals $(\mathrm{Cl})$ were calculated. We performed a test for multicollinearity among the independent variables entered into the regression model (Table S1) and confirmed that there was no multicollinearity among significant variables including oral health indicators. Multivariable regression models were performed with model 1 adjusting for the confounding factors of age, sex, income level, alcohol consumption, smoking status, body mass index, regular exercise, hypertension, diabetes mellitus, and dyslipidemia; model 2 adjusting for the variables in model 1, as well as systolic blood pressure and laboratory findings in urine and serum; and model 3 adjusting for the variables in model 2, as well as frequency of tooth brushings, periodontal disease, professional teeth scaling, dental visits for any reason, and number of teeth lost except regarding the independent variable. To investigate the trend in the HR for frequency of tooth brushings and number of teeth lost, the $p$ value for trend was estimated. Sensitivity analyses were performed in non-smokers and subjects with no alcohol consumption. The subgroup analyses according to location of oral and pharyngeal cancers (1. oral cavity and oral cancer; 2 . salivary gland cancer; 3. tonsil and pharynx cancer) were investigated by a two-tailed Wald test in the regression methods of Fine and Gray for competing risk data. All statistical analyses were performed using SAS software (version 9.2, SAS Institute, Cary, NC, USA). A p value $<0.05$ was considered statistically significant.

\section{Results}

When comparing demographics, elderly people, women, and subjects with a lower income level were more frequently observed among the excluded subjects (Table S2). The mean \pm standard deviation age of participants was $52.2 \pm 8.7$ years; $60.9 \%$ were males, $39.3 \%$ had hypertension, $9.0 \%$ had diabetes mellitus, and $25.3 \%$ were current smokers. Approximately $13.1 \%$ and $24.1 \%$ of included subjects had periodontal disease and at least one tooth lost, respectively. Based on the self-reported surveys, $40.6 \%$ of the participants brushed their teeth $\geq 3$ times/day. Approximately $23.8 \%$ of subjects had at least one professional teeth scaling per year (Table 1). 
Table 1. Baseline characteristics of the study population.

\begin{tabular}{|c|c|}
\hline Characteristics & Total \\
\hline Number of subjects & 150,774 \\
\hline Age (years) & $52.2 \pm 8.7$ \\
\hline Male sex & $91,855(60.9)$ \\
\hline \multicolumn{2}{|l|}{ Income levels } \\
\hline Fifth quintile (highest) & $59,339(39.4)$ \\
\hline Fourth quintile & $30,701(20.4)$ \\
\hline Third quintile & $20,871(13.8)$ \\
\hline Second quintile & $18,962(12.6)$ \\
\hline First quintile (lowest) & $20,665(13.7)$ \\
\hline Covered by medical aid & $236(0.2)$ \\
\hline Alcohol consumption & $71,800(47.6)$ \\
\hline \multicolumn{2}{|l|}{ Smoking status } \\
\hline Never smoker & $97,037(64.4)$ \\
\hline Former smoker & $15,590(10.3)$ \\
\hline Current smoker & $38,147(25.3)$ \\
\hline Regular physical activity & $14,570(9.7)$ \\
\hline \multicolumn{2}{|l|}{ Anthropometric measurements } \\
\hline Body mass index $\left(\mathrm{kg} / \mathrm{m}^{2}\right)$ & $23.9 \pm 2.9$ \\
\hline Systolic blood pressure (mmHg) & $126.4 \pm 17.2$ \\
\hline Diastolic blood pressure (mmHg) & $79.4 \pm 11.2$ \\
\hline \multicolumn{2}{|l|}{ Comorbidities } \\
\hline Hypertension & $59,234(39.3)$ \\
\hline Diabetes mellitus & $13,609(9.0)$ \\
\hline Dyslipidemia & $24,027(15.9)$ \\
\hline \multicolumn{2}{|l|}{ Laboratory findings } \\
\hline Total cholesterol (mg/dL) & $198.2 \pm 36.4$ \\
\hline Fasting blood sugar (mg/dL) & $97.0 \pm 29.0$ \\
\hline Aspartate aminotransferase (U/L) & $26.0 \pm 16.0$ \\
\hline Alanine aminotransferase (U/L) & $25.4 \pm 19.8$ \\
\hline Gamma glutamyl transferase (U/L) & $38.3 \pm 53.0$ \\
\hline Proteinuria ( $\geq 1+$ in dipstick test) & $4,495(3.0)$ \\
\hline \multicolumn{2}{|l|}{ Oral hygiene care } \\
\hline \multicolumn{2}{|c|}{ Frequency of tooth brushings (times/day) } \\
\hline $0-1$ & $22,111(14.7)$ \\
\hline 2 & $67,502(44.8)$ \\
\hline$\geq 3$ & $61,161(40.6)$ \\
\hline Dental visits for any reason & $63,506(42.1)$ \\
\hline Professional teeth scaling & $35,859(23.8)$ \\
\hline \multicolumn{2}{|l|}{ Oral health status } \\
\hline Periodontal disease & $19,861(13.1)$ \\
\hline \multicolumn{2}{|l|}{ Number of teeth lost } \\
\hline 0 & $114,459(75.9)$ \\
\hline $1-7$ & $32,545(21.6)$ \\
\hline $8-14$ & $2,235(1.5)$ \\
\hline$\geq 15$ & $1,535(1.0)$ \\
\hline
\end{tabular}

After a median 11.1 years of follow-up, 1,155 oral and pharyngeal cancers had occurred, which included oral cavity and oral cancer (73.8\%), salivary gland cancer (6.2\%), and tonsil and pharynx cancer (20.0\%). The estimated 10 -year event rate for oral and pharyngeal cancers was $0.76 \%$. The cumulative incidence curves for oral and pharyngeal cancers are presented in Figure 2 based on frequency of tooth brushings, professional teeth scaling, dental visits for any reason, and number of teeth lost. The risk of oral and pharyngeal cancers was lower when a subject had better oral hygiene, for example, frequent tooth brushing, frequent dental visits, and professional teeth scaling. In contrast, poor oral health status, including a greater number of teeth lost, was associated with a higher risk of oral and pharyngeal cancers.

Based on multivariable regression, frequent tooth brushing (three or more times per day) was significantly associated with a lower risk of oral and pharyngeal cancers (HR: $0.75,95 \% \mathrm{Cl}: 0.64-0.89, p=0.001$, $p$ for trend <0.001 in model 1; HR: $0.76,95 \%$ Cl: $0.64-0.90, p=0.002$, $p$ for trend=0.001 in model 2; HR: 0.79 , $95 \%$ Cl: $0.66-0.94, p=0.007, p$ for trend $=0.005$ in model 3) (Table 2 and Table S3). An increased number of teeth lost was positively related to the occurrence of oral and pharyngeal cancers based on multivariable analysis ( $p<0.001$ in models 1,2 , and 3 ). Interaction effect between number of teeth lost and age, smoking, alcohol consumption, and periodontal disease was not shown ( $p$ value $=0.467,0.872,0.136$, and 0.502 , respectively). Having lost more than 15 teeth was positively associated with increased risk of oral and pharyngeal cancers (HR: 1.71, 95\% Cl: 1.26-2.31, $p=0.001$ in model 1; HR: $1.68,95 \%$ Cl: $1.24-2.28$, p<0.001 in model 2; HR: 1.66, 95\% Cl: $1.22-2.25, p=0.001$ in model 3) (Table 2 and Table S3). However, adjusting for confounding factors, the statistical significance of the relationship between professional teeth scaling and dental visits for any reason and risk of future occurrence of oral and pharyngeal cancers was diminished in models 1-3 (Table 2 and Table S3). Paradoxically, the presence of periodontal disease insignificantly decreased the occurrence of oral and pharyngeal cancers (HR: $0.79,95 \% \mathrm{Cl}: 0.65-1.02, p=0.069$ in model 1; HR: 0.79, 95\% Cl: 0.66-1.03, p=0.066 in model 2; HR: $0.80,95 \%$ Cl: 0.65-1.03, $\mathrm{p}=0.063$ in model 3) (Table 2).

In sensitivity analyses, the association of frequent tooth brushing and number of teeth lost with the risk of occurrence of oral and pharyngeal cancers was consistently noted in non-smokers and subjects with no alcohol consumption (Table S4-S8). In subgroup analysis, the relationship between frequent tooth brushing and number of teeth lost and the risk of occurrence of oral and pharyngeal cancers was consistently noted in oral cavity and oral cancer (Table 99 
and S10). The number of teeth lost $(\geq 15)$ and dental visits for any reason were associated with future risk of the occurrence of salivary gland cancer (Table S11). In contrast, periodontal disease and parameters of oral health were not related to the occurrence of tonsil and pharynx cancer (Table S12).

Table 2. Risk of oral and pharyngeal cancers based on periodontal disease and parameters of oral health. 


\begin{tabular}{|c|c|c|c|c|c|c|c|c|c|c|c|}
\hline \multirow{2}{*}{$\begin{array}{l}\text { Number } \\
\text { of } \\
\text { subjects }\end{array}$} & \multirow{2}{*}{$\begin{array}{c}\text { Number } \\
\text { of } \\
\text { events }\end{array}$} & \multirow{2}{*}{$\begin{array}{l}\text { Follow- } \\
\text { up } \\
\text { duration } \\
\text { (person- } \\
\text { years) }\end{array}$} & \multirow{2}{*}{$\begin{array}{c}\text { Age- } \\
\text { adjusted } \\
\text { incidence } \\
\text { rate } \\
\text { (per } \\
1,000 \\
\text { person- } \\
\text { yrs, (95\% } \\
\text { CI)) }\end{array}$} & \multicolumn{2}{|c|}{ Unadjusted model } & \multicolumn{2}{|c|}{$\begin{array}{l}\text { Age, sex-adjusted } \\
\text { model }\end{array}$} & \multicolumn{2}{|c|}{$\begin{array}{c}\text { Multivariable model } \\
1\end{array}$} & \multicolumn{2}{|c|}{$\begin{array}{c}\text { Multivariable model } \\
2\end{array}$} \\
\hline & & & & $\begin{array}{c}\text { HR } \\
(95 \% \mathrm{CI})\end{array}$ & $\underset{\text { value }}{p}$ & $\underset{(95 \% \mathrm{CI})}{\mathrm{HR}}$ & $\underset{\text { value }}{p}$ & $\underset{(95 \% \mathrm{CI})}{\mathrm{HR}}$ & $\underset{\text { value }}{\mathbf{p}}$ & $\underset{(95 \% \mathrm{CI})}{\mathrm{HR}}$ & $\underset{\text { value }}{\mathrm{p}}$ \\
\hline
\end{tabular}

\begin{tabular}{|c|c|c|c|c|c|c|c|c|c|c|c|c|c|}
\hline \multicolumn{14}{|c|}{$\begin{array}{l}\text { Periodontal } \\
\text { disease }\end{array}$} \\
\hline No & 130913 & 1036 & 1499100 & $\begin{array}{c}0.52 \\
(0.49 \\
0.56)\end{array}$ & $\begin{array}{c}1 \\
\text { (Reference) }\end{array}$ & & $\begin{array}{c}1 \\
\text { (Reference) }\end{array}$ & & $\begin{array}{c}1 \\
\text { (Reference) }\end{array}$ & & $\begin{array}{c}1 \\
\text { (Reference) }\end{array}$ & & ( \\
\hline Yes & 19861 & 119 & 225247 & $\begin{array}{c}0.39 \\
(0.33 \\
0.47)\end{array}$ & $\begin{array}{c}0.76 \\
(0.63,0.92)\end{array}$ & 0.004 & $\begin{array}{c}0.78 \\
(0.65,0.94)\end{array}$ & 0.011 & $\begin{array}{c}0.79 \\
(0.65,1.02)\end{array}$ & 0.069 & $\begin{array}{c}0.79 \\
(0.66,1.03)\end{array}$ & 0.066 & ( \\
\hline \multicolumn{14}{|c|}{$\begin{array}{l}\text { Frequency } \\
\text { of tooth } \\
\text { brushings } \\
\text { (times/day) }\end{array}$} \\
\hline $0-1$ & 22111 & 240 & 248224 & $\begin{array}{c}0.59 \\
(0.52, \\
0.68)\end{array}$ & $\begin{array}{c}1 \\
\text { (Reference) }\end{array}$ & & $\begin{array}{c}1 \\
\text { (Reference) }\end{array}$ & & $\begin{array}{c}1 \\
\text { (Reference) }\end{array}$ & & $\begin{array}{c}1 \\
\text { (Reference) }\end{array}$ & & ( \\
\hline 2 & 67502 & 587 & 774302 & $\begin{array}{c}0.55 \\
(0.50 \\
0.60)\end{array}$ & $\begin{array}{c}0.80 \\
(0.69,0.93)\end{array}$ & 0.004 & $\begin{array}{c}0.90 \\
(0.78,1.05)\end{array}$ & 0.185 & $\begin{array}{c}0.91 \\
(0.78,1.06)\end{array}$ & 0.240 & $\begin{array}{c}0.92 \\
(0.79,1.07)\end{array}$ & 0.263 & ( \\
\hline$\geq 3$ & 61161 & 328 & 701821 & $\begin{array}{c}0.43 \\
(0.38 \\
0.48)\end{array}$ & $\begin{array}{c}0.49 \\
(0.42,0.58)\end{array}$ & $<.001$ & $\begin{array}{c}0.72 \\
(0.61,0.85)\end{array}$ & 0.001 & $\begin{array}{c}0.75 \\
(0.64,0.89)\end{array}$ & 0.001 & $\begin{array}{c}0.76 \\
(0.64,0.90)\end{array}$ & 0.002 & ( \\
\hline $\begin{array}{l}\text { P for } \\
\text { trend* }\end{array}$ & & & & & $<.001$ & & $<.001$ & & $<.001$ & & 0.001 & & \\
\hline \multicolumn{14}{|c|}{$\begin{array}{l}\text { Dental visits } \\
\text { for any } \\
\text { reason }\end{array}$} \\
\hline No & 87268 & 703 & 995817 & $\begin{array}{c}0.52 \\
(0.48 \\
0.57)\end{array}$ & $\begin{array}{c}1 \\
\text { (Reference) }\end{array}$ & & $\begin{array}{c}1 \\
\text { (Reference) }\end{array}$ & & $\begin{array}{c}1 \\
\text { (Reference) }\end{array}$ & & $\begin{array}{c}1 \\
\text { (Reference) }\end{array}$ & & ( \\
\hline Yes & 63506 & 452 & 728530 & $\begin{array}{c}0.49 \\
(0.44 \\
0.54)\end{array}$ & $\begin{array}{c}0.88 \\
(0.79,0.99)\end{array}$ & 0.040 & $\begin{array}{c}0.98 \\
(0.87,1.10)\end{array}$ & 0.681 & $\begin{array}{c}0.99 \\
(0.88,1.12)\end{array}$ & 0.928 & $\begin{array}{c}1.00 \\
(0.89,1.12)\end{array}$ & 0.949 & ( \\
\hline
\end{tabular}

\begin{tabular}{|c|c|c|c|c|c|c|c|c|c|c|c|c|c|}
\hline $\begin{array}{l}\text { Profess } \\
\text { teeth } \\
\text { scaling }\end{array}$ & & & & & & & & & & & & & \\
\hline No & 114915 & 960 & 1311583 & $\begin{array}{c}0.53 \\
(0.49 \\
0.57)\end{array}$ & $\begin{array}{c}1 \\
\text { (Reference) }\end{array}$ & & $\begin{array}{c}1 \\
\text { (Reference) }\end{array}$ & & $\begin{array}{c}1 \\
\text { (Reference) }\end{array}$ & & $\begin{array}{c}1 \\
\text { (Reference) }\end{array}$ & & ( \\
\hline Yes & 35859 & 195 & 412764 & $\begin{array}{c}0.44 \\
(0.38 \\
0.50)\end{array}$ & $\begin{array}{c}0.65 \\
(0.56,0.76)\end{array}$ & $<.001$ & $\begin{array}{c}0.86 \\
(0.73,1.00)\end{array}$ & 0.050 & $\begin{array}{c}0.89 \\
(0.76,1.04)\end{array}$ & 0.133 & $\begin{array}{c}0.89 \\
(0.76,1.04)\end{array}$ & 0.144 & ( \\
\hline \multicolumn{14}{|c|}{$\begin{array}{l}\text { Number of } \\
\text { teeth lost }\end{array}$} \\
\hline 0 & 114459 & 749 & 1314108 & $\begin{array}{c}0.47 \\
(0.43 \\
0.51)\end{array}$ & $\begin{array}{c}1 \\
\text { (Reference) }\end{array}$ & & $\begin{array}{c}1 \\
\text { (Reference) }\end{array}$ & & $\begin{array}{c}1 \\
\text { (Reference) }\end{array}$ & & $\begin{array}{c}1 \\
\text { (Reference) }\end{array}$ & & ( \\
\hline $1-7$ & 32545 & 313 & 370227 & $\begin{array}{c}0.61 \\
(0.54 \\
0.69)\end{array}$ & $\begin{array}{c}1.47 \\
(1.29,1.68)\end{array}$ & $<.001$ & $\begin{array}{c}1.34 \\
(1.17,1.53)\end{array}$ & $<.001$ & $\begin{array}{c}1.30 \\
(1.14,1.48)\end{array}$ & 0.001 & $\begin{array}{c}1.30 \\
(1.13,1.48)\end{array}$ & $<.001$ & ( \\
\hline 8-14 & 2235 & 44 & 24295 & $\begin{array}{c}0.75 \\
(0.55 \\
1.01)\end{array}$ & $\begin{array}{c}3.02 \\
(2.23,4.10)\end{array}$ & $<.001$ & $\begin{array}{c}1.56 \\
(1.15,2.13)\end{array}$ & 0.005 & $\begin{array}{c}1.51 \\
(1.11,2.06)\end{array}$ & 0.009 & $\begin{array}{c}1.49 \\
(1.10,2.04)\end{array}$ & 0.011 & ( \\
\hline$\geq 15$ & 1535 & 49 & 15717 & $\begin{array}{c}0.88 \\
(0.65 \\
1.19)\end{array}$ & $\begin{array}{c}4.93 \\
(3.69,6.59)\end{array}$ & $<.001$ & $\begin{array}{c}1.73 \\
(1.28,2.34)\end{array}$ & $<.001$ & $\begin{array}{c}1.71 \\
(1.26,2.31)\end{array}$ & 0.001 & $\begin{array}{c}1.68 \\
(1.24,2.28)\end{array}$ & $<.001$ & ( \\
\hline $\begin{array}{l}\text { P for } \\
\text { trend }\end{array}$ & & & & & $<.001$ & & $<.001$ & & $<.001$ & & $<.001$ & & \\
\hline
\end{tabular}




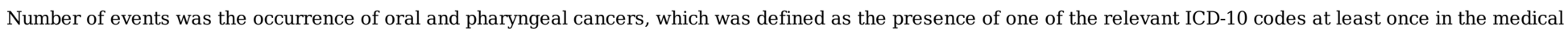
treatment database in 11.1 years of follow-up.

Event rates were reported as 11.1-year event rates (\%).

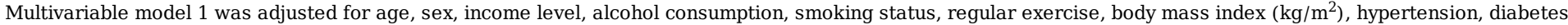
mellitus, and dyslipidemia.

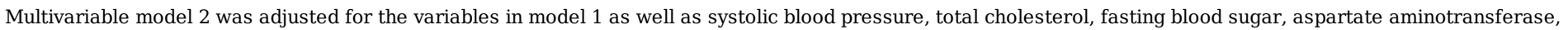
alanine aminotransferase, gamma glutamyl transferase, and proteinuria.

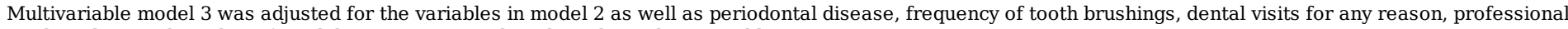
teeth scaling, and number of teeth lost except regarding the independent variable.

CI, confidence interval; HR, hazard ratio.

*: The trend test for hazard ratios

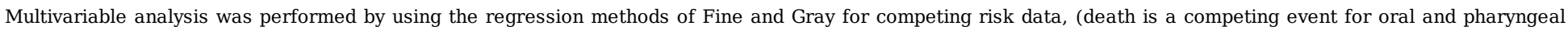
cancers).

\section{Discussion}

Our findings from the present study are that: 1) frequent tooth brushing may lower the occurrence of oral and pharyngeal cancers even after adjusting for important confounding factors, and 2) poor oral health evidenced by a greater number of teeth lost was independently related to future occurrence of oral and pharyngeal cancers.

In previous studies, infrequent tooth brushing was shown to be associated with oral and pharyngeal cancers, regardless of smoking and alcohol consumption [25-27]. Tooth brushing less than once a day was also associated with an increased risk of tongue cancer (odds ratio: 2.1) and cancer in other parts of the mouth (odds ratio: 2.4) [27]. In a case-control study of Chinese subjects, the risk of oral cancer was 6.9-fold greater for males and 2.5-fold for females in subjects who infrequently brushed their teeth [5]. Results in another European study indicated that daily brushing was a protective factor against developing oral cancer (odds ratio: 0.41) [28]. Moreover, in previous pooled analysis, pharyngeal cancer was inversely associated with frequent tooth brushing [20]. The results from the present study are in agreement with the above-mentioned studies and provide additional evidence for the longitudinal relationship between tooth brushing and decreased occurrence of oral and pharyngeal cancers.

In the present study, a positive association between loss of multiple teeth and the occurrence of oral and pharyngeal cancers was observed. This association has been consistently reported in previous studies. In a previous meta-analysis of prospective cohort studies, teeth lost was significantly related to a higher occurrence of both oral cancer (relative risk:1.80; 95\% Cl, 1.30-2.30; $\mathrm{p}<0.001$ ) and pharyngeal cancer (relative risk:1.14; 95\% Cl, 1.05-1.23; $\mathrm{p}<0.001$ ) [29]. In addition, for dose-response meta-analyses, teeth lost was significantly related to a higher occurrence of oral cancer. An increase in the odds ratio by 0.03 was observed for each additional tooth lost [30]. Teeth lost may be closely related to failure to maintain oral hygiene (i.e., infrequent tooth brushing, dental visits, and professional teeth scaling); exposure to cancer-inducing factors such as smoking, nitrosamines, or alcohol; and secondary inflammation or infection of the oral cavity [31, 32]. Because these factors may promote malignancy [33, 34], our hypothesis is plausible.

To investigate which site of oral and pharyngeal cancers is most associated with oral hygiene, we analyzed the site-specific risk according to oral disease and hygiene. For the oral cavity cancers, the results were quite similar to the overall result of the present study (Table S9 and S10). This result seems supportive of the hypothesis that poor oral hygiene can mediate cancer most effectively in the oral cavity. On the other hand, for the salivary gland cancer, risk of cancer occurrence showed significant association with dental visit for any reason (Table S11). This contradictory looking result may because the dental visit for any reason was a variable dependent on the report of the subjects, which is vulnerable for the recall bias, or may because salivary gland is a very rare disease and people who had undergone frequent dental care are more likely to be found. For the tonsil and pharyngeal cancer, risk of cancer occurrence was not significantly associated with any indicators of oral health and oral hygiene in this study.

In the present study, visiting the dentist and professional teeth scaling were associated with a decreased occurrence of oral and pharyngeal cancers. However, infrequent dental visits were related to an increased occurrence of oral and pharyngeal cancers based on univariate analysis. These results are consistent with previous studies $[7,25,35]$. Conversely, after adjusting for various important confounding factors, the association between dental visits and professional teeth scaling and the occurrence of malignancy was not statistically significant. These results may be due to other factors, which are more likely associated with malignancy than dental visits and professional teeth scaling.

Even if it was insignificant, paradoxically, our data showed that the presence of periodontal disease was associated with a decreased occurrence of oral and pharyngeal cancers. This finding might be explained by the possible use of anti-inflammatory drugs, such as nonsteroidal anti-inflammatory drugs (NSAIDs), by the subjects with periodontal disease. NSAID is a group of drugs commonly prescribed during the treatment of periodontal disease. Though the results are not consistent, the potential chemo-preventive effect of NSAIDs for oral and pharyngeal cancer had been studied and suggested recently [36-39]. However, it is difficult to say that the effect of NSAIDs use exceed that of periodontal disease itself on the occurrence of oral and pharyngeal cancer. Moreover, the number of subjects who had taken NSAIDs or the amount and frequency of NSAIDs prescription were not evaluated in this study. Another explanation is that the definition of periodontal disease according to ICD-10, as applied in our study, does not incorporate recently published classification criteria and definitions for cases of periodontal disease [40].

The present study had several limitations. First, although this was a longitudinal study, the cohort was retrospectively analyzed without intervention, and therefore information bias could not be excluded, and establishing causal relationships was not possible. Second, many subjects were excluded before analysis due to missing values in their oral health status data. Because the oral examination was not a mandatory test item, this exclusion may lead to a selection bias, leaving the subjects with healthier behaviors in the study dataset. Third, although we used a washout period of one year before the index date, a 
hidden malignancy at baseline remains a possibility. Fourth, because oral hygiene behaviors (professional teeth scaling, dental visits for any reason, and frequency of tooth brushings) were based on self-reported surveys which are subject to recall bias, the measure of $40 \%$ of the participants brushing teeth $\geq 3$ times/day might be considered overreporting by the subjects. Fifth, although parameters of oral health can be altered during follow-up, our study did not take into account these time-varying factors. Sixth, although HPV infection and treatment were important covariates for the occurrence of oral and pharyngeal cancers, because treatment for HPV infections was not covered by national insurance, our health claim data could not adjust for HPV-related parameters. Seventh, the NHIS-HEALS cohort dataset does not supply information about the education or occupations of the subjects. Therefore, income level was the only adjusted variable that reflects socioeconomic status. Finally, because this is a cohort study with a large number of subjects but no sample size calculation, we cannot completely rule out the possibility that the association between oral health and the occurrence of oral and pharyngeal cancers is statistically significant only due to the large sample size. Nevertheless, the present study had several strengths. Contrary to previous studies, which were mostly case-control studies, this was a nationwide, general population-based longitudinal study. In addition, this study included a relatively large sample size. Distinct from previous studies, various risk factors were included, such as comorbidities, laboratory findings, alcohol consumption, smoking status, and oral hygiene, and were adjusted in multivariate analysis in this study.

\section{Conclusions}

Better oral hygiene behaviors, particularly brushing teeth $\geq 3$ times a day, were associated with a reduced risk of oral and pharyngeal cancers. Poor oral hygiene, especially the greater number of teeth lost, was associated with an increased risk of oral and pharyngeal cancers. Therefore, improving oral hygiene may have a significant contribution to lowering the risk of oral and pharyngeal cancers.

\section{List Of Abbreviations}

Human papillomavirus: HPV

National Health Insurance System: NHIS

National Health Insurance System-Health Screening Cohort: NHIS-HEALS

International Statistical Classification of Diseases and Related Health Problems: ICD

Hazard ratio: HR

Confidence interval: $\mathrm{Cl}$

Nonsteroidal anti-inflammatory drugs: NSAIDs

Ewha Womans University of College of Medicine Medical Center: EUMC

\section{Declarations}

\section{Ethics approval and consent to participate}

Our study was approved by the Institutional Review Board of the Ewha Womans University of College of Medicine (EUMC 2018-01-067); Because of the retrospective anonymized dataset, the requirement for written informed consent from participants was waived.

\section{Consent for publication}

Not applicable

\section{Availability of data and materials}

The data that support the findings of this study were used under license from NHIS-HEALS for the current study and are therefore not publicly available. However, data can be made available by the authors upon reasonable request and with permission from the National Health Insurance System.

\section{Competing interests}

The authors declare that they have no competing interests

\section{Source of funding}

This work was supported by a grant from the Basic Science Research Program through the National Research Foundation of Korea, funded by the Ministry of Education (2018R1D1A1B07040959).

\section{Authors' contributions}

H.G.W. is expected to have made substantial contributions to the conceptualization, methodology, software, investigation, resources, data curation, writing (original draft preparation), writing (review and editing), and visualization. K.L. is expected to have made substantial contributions to the conceptualization, methodology, software, formal analysis, investigation, resources, writing (original draft preparation), writing (review and editing), and visualization. J.S.L. is 
expected to have made substantial contributions to the conceptualization, methodology, software, formal analysis, investigation, resources, data curation, writing (original draft preparation), and visualization. J.K. is expected to have made substantial contributions to the conceptualization, methodology, software, investigation, resources, data curation, writing (review and editing), and visualization. Y.C. is expected to have made substantial contributions to the conceptualization, methodology, software, validation, investigation, writing (review and editing), visualization, and supervision. J.W.K. is expected to have made substantial contributions to the conceptualization, methodology, software, validation, investigation, writing (review and editing), visualization, and supervision. T.J.S is expected to have made substantial contributions to the conceptualization, methodology, software, validation, formal analysis, investigation, resources, data curation, writing (original draft preparation), writing (review and editing), visualization, supervision, project administration, and funding acquisition.

\section{Acknowledgements}

Not applicable

\section{References}

1. Warnakulasuriya S: Global epidemiology of oral and oropharyngeal cancer. Oral Oncol 2009, 45(4-5):309-316.

2. Saman DM: A review of the epidemiology of oral and pharyngeal carcinoma: update. Head Neck Oncol 2012, 4:1.

3. Khode SR, Dwivedi RC, Rhys-Evans P, Kazi R: Exploring the link between human papilloma virus and oral and oropharyngeal cancers. J Cancer Res Ther 2014, 10(3):492-498.

4. Marcenes W, Kassebaum NJ, Bernabe E, Flaxman A, Naghavi M, Lopez A, Murray CJ: Global burden of oral conditions in 1990-2010: a systematic analysis. J Dent Res 2013, 92(7):592-597.

5. Zheng TZ, Boyle P, Hu HF, Duan J, Jian PJ, Ma DQ, Shui LP, Niu SR, Scully C, MacMahon B: Dentition, oral hygiene, and risk of oral cancer: a case-control study in Beijing, People's Republic of China. Cancer Causes Control 1990, 1(3):235-241.

6. Graham S, Dayal H, Rohrer T, Swanson M, Sultz H, Shedd D, Fischman S: Dentition, diet, tobacco, and alcohol in the epidemiology of oral cancer. J Natl Cancer Inst 1977, 59(6):1611-1618

7. Rosenquist K, Wennerberg J, Schildt EB, Bladstrom A, Goran Hansson B, Andersson G: Oral status, oral infections and some lifestyle factors as risk factors for oral and oropharyngeal squamous cell carcinoma. A population-based case-control study in southern Sweden. Acta Otolaryngol 2005, 125(12):1327-1336.

8. Roxburgh CS, McMillan DC: Cancer and systemic inflammation: treat the tumour and treat the host. Br J Cancer 2014, 110(6):1409-1412.

9. Feller L, Altini M, Lemmer J: Inflammation in the context of oral cancer. Oral Oncol 2013, 49(9):887-892.

10. Moore MM, Chua W, Charles KA, Clarke SJ: Inflammation and cancer: causes and consequences. Clin Pharmacol Ther 2010, 87(4):504-508.

11. Lissowska J, Pilarska A, Pilarski P, Samolczyk-Wanyura D, Piekarczyk J, Bardin-Mikollajczak A, Zatonski W, Herrero R, Munoz N, Franceschi S: Smoking, alcohol, diet, dentition and sexual practices in the epidemiology of oral cancer in Poland. Eur J Cancer Prev 2003, 12(1):25-33.

12. Javed F, Warnakulasuriya S: Is there a relationship between periodontal disease and oral cancer? A systematic review of currently available evidence. Crit Rev Oncol Hematol 2016, 97:197-205.

13. Ye L, Jiang Y, Liu W, Tao H: Correlation between periodontal disease and oral cancer risk: A meta-analysis. J Cancer Res Ther 2016, 12(Supplement):C237C240.

14. Gupta B, Kumar N, Johnson NW: Periodontitis, oral hygiene habits, and risk of upper aerodigestive tract cancers: a case-control study in Maharashtra, India. Oral Surg Oral Med Oral Pathol Oral Radiol 2020.

15. Gupta B, Bray F, Kumar N, Johnson NW: Associations between oral hygiene habits, diet, tobacco and alcohol and risk of oral cancer: A case-control study from India. Cancer Epidemiol 2017, 51:7-14.

16. Kim MK, Han K, Koh ES, Kim HS, Kwon HS, Park YM, Yoon KH, Lee SH: Variability in Total Cholesterol Is Associated With the Risk of End-Stage Renal Disease: A Nationwide Population-Based Study. Arterioscler Thromb Vasc Biol 2017, 37(10):1963-1970.

17. Song SO, Jung CH, Song YD, Park CY, Kwon HS, Cha BS, Park JY, Lee KU, Ko KS, Lee BW: Background and data configuration process of a nationwide population-based study using the korean national health insurance system. Diabetes Metab J 2014, 38(5):395-403.

18. Seong SC, Kim YY, Park SK, Khang YH, Kim HC, Park JH, Kang HJ, Do CH, Song JS, Lee EJ et al: Cohort profile: the National Health Insurance ServiceNational Health Screening Cohort (NHIS-HEALS) in Korea. BMJ Open 2017, 7(9):e016640.

19. Park SY, Kim SH, Kang SH, Yoon CH, Lee HJ, Yun PY, Youn TJ, Chae IH: Improved oral hygiene care attenuates the cardiovascular risk of oral health disease: a population-based study from Korea. Eur Heart J 2019, 40(14):1138-1145.

20. Hashim D, Sartori S, Brennan P, Curado MP, Wunsch-Filho V, Divaris K, Olshan AF, Zevallos JP, Winn DM, Franceschi S et al: The role of oral hygiene in head and neck cancer: results from International Head and Neck Cancer Epidemiology (INHANCE) consortium. Ann Oncol 2016, 27 (8):1619-1625.

21. Hashibe M, Brennan P, Benhamou S, Castellsague X, Chen C, Curado MP, Dal Maso L, Daudt AW, Fabianova E, Fernandez L et al: Alcohol drinking in never users of tobacco, cigarette smoking in never drinkers, and the risk of head and neck cancer: pooled analysis in the International Head and Neck Cancer Epidemiology Consortium. J Natl Cancer Inst 2007, 99(10):777-789.

22. Seo HJ, Oh IH, Yoon SJ: A comparison of the cancer incidence rates between the national cancer registry and insurance claims data in Korea. Asian Pac $J$ Cancer Prev 2012, 13(12):6163-6168. 
23. Lee JH, Choi JK, Jeong SN, Choi SH: Charlson comorbidity index as a predictor of periodontal disease in elderly participants. $J$ Periodontal Implant Sci 2018, 48(2):92-102.

24. Lee JH, Lee JS, Park JY, Choi JK, Kim DW, Kim YT, Choi SH: Association of Lifestyle-Related Comorbidities With Periodontitis: A Nationwide Cohort Study in Korea. Medicine (Baltimore) 2015, 94(37):e1567.

25. Marques LA, Eluf-Neto J, Figueiredo RA, Gois-Filho JF, Kowalski LP, Carvalho MB, Abrahao M, Wunsch-Filho V: Oral health, hygiene practices and oral cancer. Rev Saude Publica 2008, 42(3):471-479.

26. Blot WJ, Winn DM, Fraumeni JF, Jr.: Oral cancer and mouthwash. J Nat/ Cancer Inst 1983, 70(2):251-253.

27. Velly AM, Franco EL, Schlecht N, Pintos J, Kowalski LP, Oliveira BV, Curado MP: Relationship between dental factors and risk of upper aerodigestive tract cancer. Oral Oncol 1998, 34(4):284-291

28. Moreno-Lopez LA, Esparza-Gomez GC, Gonzalez-Navarro A, Cerero-Lapiedra R, Gonzalez-Hernandez MJ, Dominguez-Rojas V: Risk of oral cancer associated with tobacco smoking, alcohol consumption and oral hygiene: a case-control study in Madrid, Spain. Oral Oncol 2000, 36(2):170-174.

29. Shi J, Leng W, Zhao L, Deng C, Xu C, Wang J, Wang Y, Peng X: Tooth loss and cancer risk: a dose-response meta analysis of prospective cohort studies. Oncotarget 2018, 9(19):15090-15100.

30. Michaud DS, Fu Z, Shi J, Chung M: Periodontal Disease, Tooth Loss, and Cancer Risk. Epidemiol Rev 2017, 39(1):49-58.

31. Abnet CC, Qiao YL, Mark SD, Dong ZW, Taylor PR, Dawsey SM: Prospective study of tooth loss and incident esophageal and gastric cancers in China. Cancer Causes Control 2001, 12(9):847-854.

32. Simila T, Virtanen Jl: Association between smoking intensity and duration and tooth loss among Finnish middle-aged adults: The Northern Finland Birth Cohort 1966 Project. BMC Public Health 2015, 15:1141.

33. Gankhuyag N, Lee KH, Cho JY: The Role of Nitrosamine (NNK) in Breast Cancer Carcinogenesis. J Mammary Gland Biol Neoplasia 2017, 22(3):159-170.

34. Multhoff G, Molls M, Radons J: Chronic inflammation in cancer development. Front Immunol 2011, 2:98.

35. Gupta B, Kumar N, Johnson NW: Evidence of past dental visits and incidence of head and neck cancers: a systematic review and meta-analysis. Syst Rev 2019, 8(1):43.

36. Ahmadi N, Goldman R, Seillier-Moiseiwitsch F, Noone AM, Kosti O, Davidson BJ: Decreased risk of squamous cell carcinoma of the head and neck in users of nonsteroidal anti-inflammatory drugs. Int J Otolaryngol 2010, 2010:424161.

37. Becker C, Wilson JC, Jick SS, Meier CR: Non-steroidal anti-inflammatory drugs and the risk of head and neck cancer: A case-control analysis. Int J Cancer 2015, 137(10):2424-2431.

38. Tang L, Hu H, Liu H, Jian C, Wang H, Huang J: Association of nonsteroidal anti-inflammatory drugs and aspirin use and the risk of head and neck cancers: a meta-analysis of observational studies. Oncotarget 2016, 7(40):65196-65207.

39. Saka Herran C, Jane-Salas E, Estrugo Devesa A, Lopez-Lopez J: Protective effects of metformin, statins and anti-inflammatory drugs on head and neck cancer: A systematic review. Oral Oncol 2018, 85:68-81.

40. Caton JG, Armitage G, Berglundh T, Chapple ILC, Jepsen S, Kornman KS, Mealey BL, Papapanou PN, Sanz M, Tonetti MS: A new classification scheme for periodontal and peri-implant diseases and conditions - Introduction and key changes from the 1999 classification. J Periodonto/ 2018, 89 Suppl 1:S1-S8.

\section{Figures}




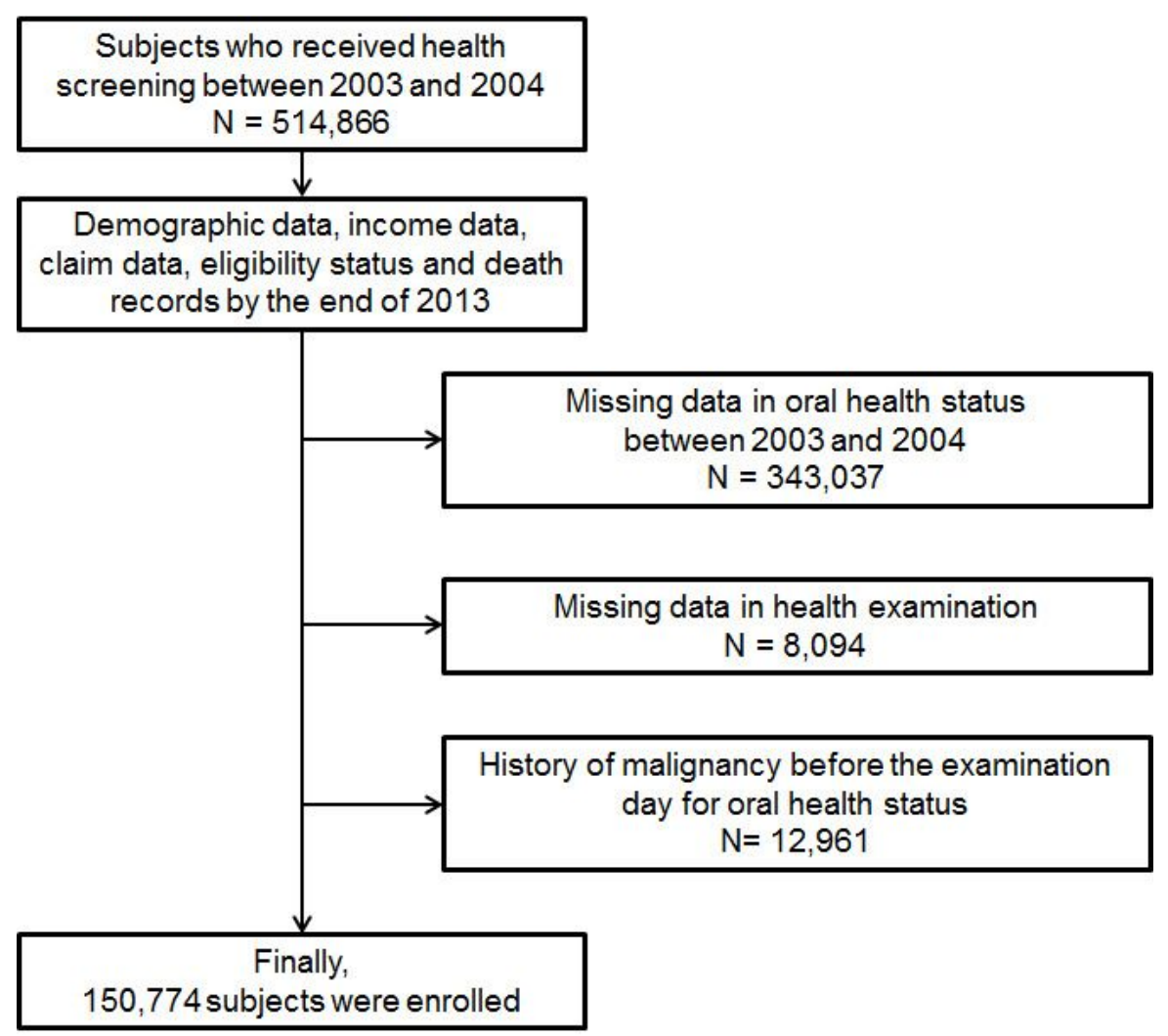

Figure 1

Flow chart of the study subjects. 

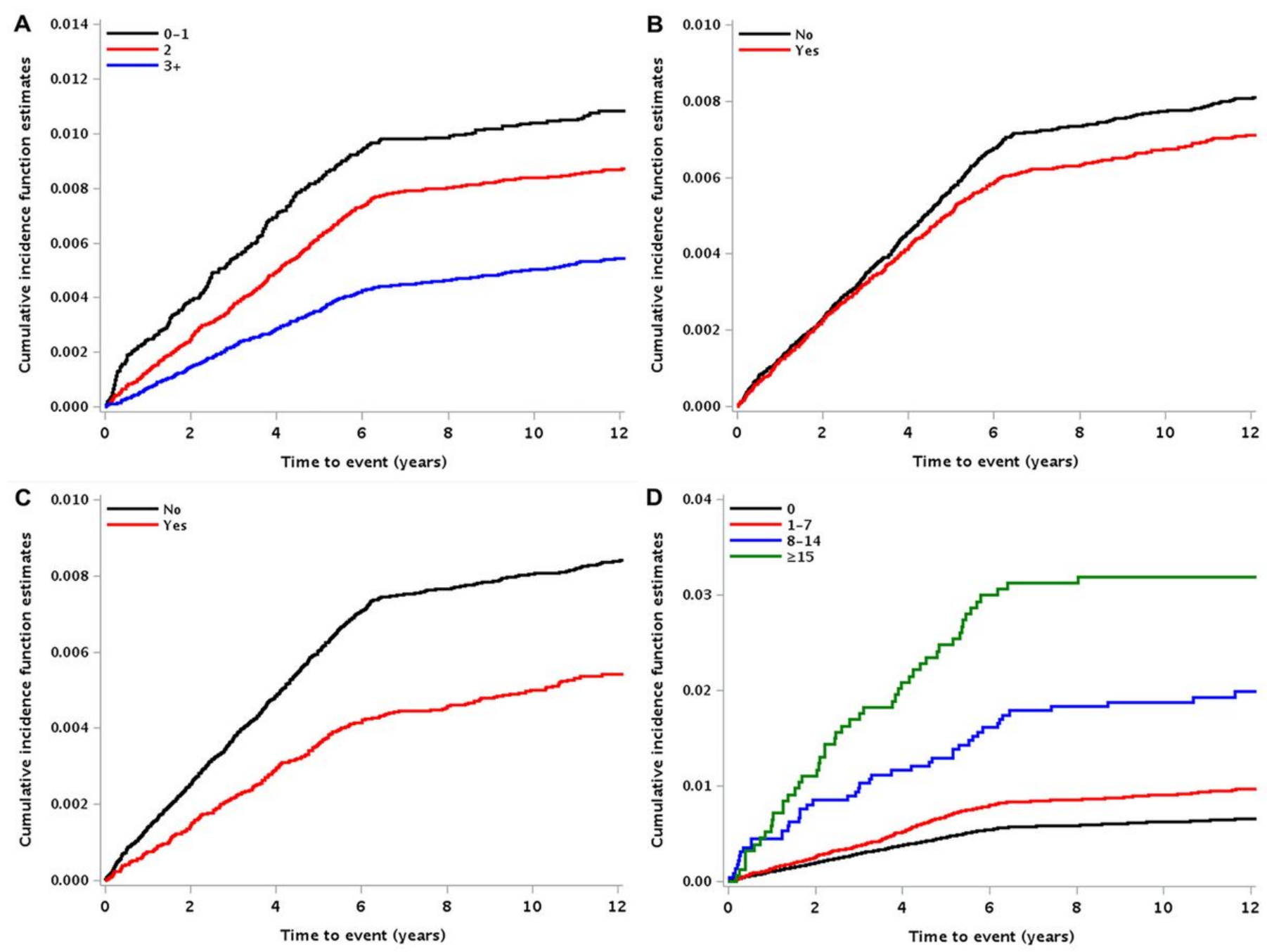

\section{Figure 2}

Cumulative incidence curves were analyzed by Gray's Test to determine the association between parameters of oral health and occurrence of oral and pharyngeal cancers. The curves show that the risk of oral and pharyngeal cancers depends on the frequency of tooth brushings $(A)(p<0.001)$, dental visits for any reason $(B)(p=0.040)$, professional teeth scaling $(C)(p<0.001)$, and number of teeth lost $(D)(p<0.001)$.

\section{Supplementary Files}

This is a list of supplementary files associated with this preprint. Click to download.

- 20200526Additionalfile1plainfinal.pdf 